that this happened is not conclusive. During the decade between his mother's eventual acquittal in 1621 and his own death, Kepler took time off from the preparation of his major works of this period to embellish the original text of the Dream with several times its own length of footnotes giving those literary and scientific explanations of the narrative that had been proved necessary by bitter experience.

Most of the scientific part of the Dream is a sober exploration of the astronomical phenomena observable from the Moon as a result of its orbital motion with one face permanently turned towards the Earth; this part would be entirely acceptable to-day apart from the fact that the Sun's distance is underestimated by a factor of six. However, Kepler also believed that the Moon had air, water and inhabitants who sheltered from the extremes of heat and cold in caves; the arguments on these subjects in the notos, and the precautions suggested for the journey to the Moon, throw an interesting sidelight on his improssive physical knowledgo.

John Lear has performed a useful service in commissioning this excellent translation and in providing a fascinating introduction in which the importance of this forgotten work is pointed out and the baleful effects of the misinterpretation of the 1609 manuscript are reconstructed for the first time on the basis of the notes in the 1634 edition. My only eriticism refers to one passage where Lear seems to have confused nautical miles with statute miles and consequently credits Kopler with a less accurate estimate of the Moon's distance than he actually possessed.

Bernard Pagex

\section{MOON AND PLANETS}

\section{Lunar and Planetary Surface Conditions}

By N. A. Weil. (Advances in Space Science and Technology, Supplement 2.) Pp. ix +222 . (New York and London: Academic Press, 1965.) $80 s$.

$\mathrm{T}$ HE majority of books devoted to so wide a subject as planetary physics are composed of specialist sections that an editor attempts (rarely with high success) to weld together. Perhaps, in such cases, the initial conditions are not sufficiently firmly stipulated to ensure uniformity of style; or the authors who are selected are not able to present a full eross-section of the field defined in the title, and hence there are glaring omissions from the presentation.

Possibly these drawbacks may be overcome if one man alone prepares the whole account. Yet, with the rapidly multiplying amount of lunar and planetary literature, can one author have a sufficiontly wide knowledge of the many and varied subjects involved to be in a position to present an authoritative review of the astronomy, physies, geology, and biological aspects of the planets? In Lunar and Planetary Surface Conditions Dr. Weil has bravely attempted this task.

An introduction serves to review the present hypotheses on the origin of the Solar System and describes the methods of acquiring planetary data. Approximately one-third of the book pertains to lunar studies-principally the surface aspocts of the Moon-and the remainder deals with the conditions on the terrestrial and Jovian planets.

There has been drastic selection of the 293 reforences from the fund of available literature, but they have been well chosen and, pleasingly, there has been emphasis on recent work. Omissions from Dr. Weil's arguments are extensive and frequently yield to a biased account. For example: "Three theories exist regarding the origin of the maria" (p. 44). According to the author, these are Gold's, Urey's and Baldwin's. In fact, there are othersthat of von Bülow, for example-that receive no mention although they may be even more important. Again, both the optical measurements of the way different parts of the
Moon scatter light and the polarization measurements on flat and inclined parts of the Moon point to a remarkably uniform structure of the Moon's surface layer, yet Dr. Weil writes, ". . . for exposed lunar surfaces, a totally different terrain is expected to be encountered on the maria as compared to the highlands" (p. 92). The inclusion of some arguments at the expense of others may have been imposed by the necessity for brevity, but is this justified in a review costing $80 \mathrm{~s}$.? Because of faults of this nature the book-which has a good index-will be of limited use to research workers. But the present work may be described as an excellent skeleton on which to build a future, somewhat enlarged, edition. If a second edition were to include a wider and deeper understanding of many of the vitally interesting points touched on by Dr. Weil, it could undoubtedly become of great use as a reference work.

G. Fielder

\section{A SURVEY OF THE EARTH}

\section{A Planet Called Earth}

By Prof. George Gamow. Pp. $\mathrm{x}+257$. (London: Macmillan and Co., Ltd., 1965.) 35s. net.

MORE than twenty years ago the book Biography of VI the Earth, by George Gamow, achieved wide popularity as an introduction to earth science written for the layman. There have been many scientific advances since then, and the author has wisely re-written the book completely instead of trying to patch up the original. The general plan remains the same; like its predecessor, A Planet Called Earth is informative and well written, so that it will no doubt be equally successful.

The first three chapters are mainly astronomical, and concern the formation of the Earth and other bodies of the Solar System, together with brief descriptions of the Moon and planets. This section is needed, because the Earth is, after all, only one of nine planets, and the comparisons between it and our neighbour worlds are well worth making. It is interesting to note that the author tends to favour the theory that the Earth and Moon were onco one body, and that the Moon broke away in the fashion supposed by George Darwin in his book written during the nineteenth century. Most authorities have the gravest doubts about this process, but Gamow is careful to emphasize that there is no general agreement about the birth of the Moon.

The rest of the text deals with the Earth itself; its internal constitution, the shaping of the world map, weather and climate, and the atmosphere. The nature and origin of life, and the Earth's future, are also dealt with in a readable, concise manner.

The material has been selected with skill, and has been presented in a most attractive form, so that the reador with no previous scientific knowledge will be able to follow it throughout; mathematics are to all intents and purposes excluded. The line drawings are good, and the photographs are satisfactorily reproduced. It must be added, unfortunately, that there are a few slips, mainly in the astronomical section; for example, there are more than the stated $40,000,000,000$ stars in our Galaxy (p. 22), and it is surely misleading to refer to a solar flare as "a tongue of flame" (p. 181). On pago 43 the author falls into the trap, common among non-selenographers, of rejecting tho volcanic theory of lunar craters simply because these main features of the Moon diffor in form from Earth volcanoes such as Vesuvius.

These are, however, minor points, and in no way detract from the excellence of the book. Within its sccpe, it is probably the best of its kind, and it will further enhance Prof. Gamow's reputation as one of the most skilful of modern scientific writers. It deserves a wide circulation, and will certainly run to many editions before it, too, needs complete re-writing.

Patrick Moore 